European journal of American studies

\title{
Autobodies: Detectives, Disorders, and Getting out of the Neighborhood
}

James Peacock

\section{OpenEdition}

\section{Journals}

Electronic version

URL: https://journals.openedition.org/ejas/17534

DOI: 10.4000/ejas. 17534

ISSN: 1991-9336

Publisher

European Association for American Studies

\section{Electronic reference}

James Peacock, "Autobodies: Detectives, Disorders, and Getting out of the Neighborhood", European journal of American studies [Online], 16-4 | 2021, Online since 20 December 2021, connection on 07 July 2022. URL: http://journals.openedition.org/ejas/17534 ; DOI: https://doi.org/10.4000/ejas. 17534

This text was automatically generated on 7 July 2022.

\section{(c) (†) \&}

Creative Commons - Attribution-NonCommercial 4.0 International - CC BY-NC 4.0 https://creativecommons.org/licenses/by-nc/4.0/ 


\title{
Autobodies: Detectives, Disorders, and Getting out of the Neighborhood
}

\author{
James Peacock
}

Between the non-identity of pure fluidity and the fixity involved in all definitionin words or in life-the American writer moves, and knows he moves.

(Tanner 17-18)

Objects in the rear-view mirror may appear closer than they are.

(Meat Loaf 1994)

\section{Introduction}

1 This article is about two detectives who appear, on the surface, to be ludicrously unsuitable for investigative work. Lionel Essrog, protagonist of Jonathan Lethem's Motherless Brooklyn (1999), has Tourette's Syndrome. Describing himself as "a carnival barker, an auctioneer, a downtown performance artist, a speaker in tongues, a senator drunk on filibuster" (Lethem 1), his gift for literary metaphor, his ability to portray his own condition, risk obscuring the fact that his manifold symptoms-including echolalia, coprolalia, obsessive motor tics-might serve him badly when a detective's guile is required.

2 In Paul Tremblay's homage to Raymond Chandler, The Little Sleep (2009), private eye Mark Genevich suffers from traumatically-induced narcolepsy. Prone to episodes of "hypnogogic hallucination" (Tremblay 6), and the "micro-sleeps" from which the novel's title derives (8), Genevich, eking out an existence in South Boston while living in an apartment owned by his mother Ellen, regards his condition as a battle with time: "that's how time works for me. My constant enemy, it attacks whenever I'm not looking" (7). And, given the gumshoe's need to ratiocinate from consideration of the empirical evidence, Genevich's occasional inability to distinguish between "dreams and reality" (5), engendered by chronological confusion, presents significant professional problems: "Time can't be measured anyway, only guessed at, and my guesses are 
usually wrong, which doesn't speak well for a guy in my line of work" (5). As in Lethem's, much of the drama and comedy of Tremblay's story derives from the detective operating on the edge of self-sabotage.

Ultimately, however (and unsurprisingly), both Essrog and Genevich win the day: within, at least, the parameters of the cases narrated in Motherless Brooklyn and The Little Sleep, they prove themselves to be successful detectives precisely because their approaches are, by necessity of their neurological conditions and their troubled histories, unpredictable and unorthodox. Although both investigators resolve the mechanical diegetic issues of who committed the crimes and for what reasons, I argue that their main achievement is an increasingly sophisticated understanding of their conditions: not the symptomologies per se-about which they demonstrate ample awareness from the outset-but the causal and circumstantial connections between their symptoms and their upbringings, traumatic experiences and, crucially, fierce attachments to their urban neighborhoods. With the self-consciousness typical of many first-person detective narrators (but metafictionally heightened in these novels, particularly Lethem's), Essrog and Genevich reveal in these literary contexts an awareness of their conditions' metaphorical symptoms-one of which is the inclination toward metaphorization itself-and the possibilities they create for, if not cure, at least deep reflection on certain idiosyncratic obsessions. Among these we must include Genevich's "mortal enemy" (39), time; absent parents; memory and nostalgia; and, as I have already suggested, local neighborhoods-for Essrog, Court Street, Brooklyn, "where it passed through Carroll Gardens and Cobble Hill" (56), and for Genevich South Boston, or "Southie."

4 My general claims might appear unsurprising: after all, detective stories are almost always about much more than "whodunit," and are invariably imbued with a vivid, organic sense of place which, Gillian Tindall argues, renders the term "setting" inadequate (Tindall 1). What I specifically propose here, however, is that these novels' symptomologies encourage deeper questioning of affective and material attachments to built environments and "homes" in a contemporary period characterized by multiple forms of mobility, deterritorialization, and displacement caused by related phenomena such as gentrification and globalization. By "symptomology," then, I refer not only to the manifestations of the protagonists' conditions, but also to the social, cultural and economic structures of feeling that both reflect and exacerbate these conditions. Key to my arguments is the proposition that Essrog and Genevich are vulnerable subjects, with "vulnerability" understood both in a conventional sensetheir conditions and their traumatic pasts make them especially susceptible to the world's dangers - and in the sense employed by Judith Butler in Precarious Life (2004)referring to the "permeable borders" of selfhood (Butler xii) and the frightening, vertiginous feeling of being open to the power of others. Like Jean-Michel Ganteau, I regard vulnerability as a useful "paradigm of the contemporary and of contemporary culture, and a template for the wounded contemporary subject" (Ganteau 4). In this context it is used in relation to the individual's complex and often bewildering participation in different spaces, places and mobilities, and to the vulnerability engendered by time itself, the haunting of the present by the past and by future possibilities.

5 Such a context invites examination of a key material and symbolic element of both novels, one in which the protagonists, especially Genevich, are especially vulnerable: 
the automobile. Since its invention, this enduringly ambiguous symbol of American modernity and mobility has proven attractive to writers for the ways in which it excites "far-reaching changes in the human experience of basic categories of time and space" (Thacker 39)-notably an "individualization" of spatiotemporality (Lothman and Schumacher 213). Embodying tensions between freedom and restriction, individualism and society, the promise of progress and the seduction of nostalgia, life-preserving close attention and postmodern distraction or "amnesiac intoxication" (Baudrillard 7), the car conspires with the characters' neurological conditions to expand the metaphorical possibilities of these novels to a point at which they threaten, like the protagonists, to spiral out of control. Genevich, taking the wheel against his better judgment toward the end of The Little Sleep, does exactly that (Tremblay 217).

6 The link between automobility and neurological conditions is made explicit by both authors, echoing, as we shall see, the deployment of metaphors of movement and stasis in scientific commentaries on, for example, Tourette's in the writings of Oliver Sacks. Genevich's narcolepsy emerges after a car accident that left him disfigured and killed his best friend (20); his "narcoleptic brain," which insists on performing familiar tasks while he is submerged in micro-sleep, he dubs "my automatic self" (10). In using chremamorphism to describe his condition, Genevich echoes Motherless Brooklyn, in which a pivotal section narrating, among other events, Essrog's drive from New York to Maine, is called "Auto Body," thus confirming the implied pun on "motor tics" that underpins all the car-related actions of the novel.

7 In this article, I first discuss recent theories of hybrid or assembled forms of selfhoodwhat our protagonists might call "automatic selves" or "autobodies"-within a contemporary, capitalist "car-system" that is "a way of life, an entire culture" and has radically reshaped landscapes and "redefined movement, pleasure and emotion in the contemporary world" (Dennis and Urry 58-9). Coining different terms such as "autoself" (Randell 664), "driver-car" (Dant 61), "automobilized person" (Katz 33) and "carson" (Böhm et al. 12), twenty-first-century sociologists and cultural theorists have increasingly sought to analyse the car not only as a commodity that exemplifies "the development of production in industrial capitalism" and "the desired object" of consumer capitalism (Dant 61), but also a material and symbolic object with the power to shape natural and built environments and produce "a range of social actions" (Dant 61) and "embodied dispositions" (Sheller 221) from the collaboration of human and machine. My engagement with these theories emphasizes what they show about contemporary individuals, vulnerability and interactions with space and mobility in order that, in later sections of this article, I can discuss the specific consequences for Essrog and Genevich as they try, maybe fail, to get out of the old neighborhood-in their minds, if not their cars.

If scholarly accounts of the car-system and its participants inevitably include observations on the material, topographical, environmental and economic effects of automobility, they are as much concerned with what Nigel Thrift, in his car-focused critical engagement with Michel de Certeau's The Practice of Everyday Life, calls the "nonrepresentational" aspects of human interaction with landscapes shaped by automobility (Thrift 43). These include: tactility; creative, idiosyncratic modes of renegotiating spaces that are ostensibly strictly regulated; the performance of behaviours and identities; affect and emotion. Mimi Sheller, noting that "car consumption" is never strictly predicated on rational decision-making, but involves the 
aesthetics, emotions and sensual promises of motoring (222), argues that the driver be considered an "emotional agent" and "relational entity" within complex social landscapes of human and technological actors. Moreover, emotion itself, at the same time it helps to structure social relations into "wider aesthetic and kinaesthetic cultures" (Sheller 223), emerges from these relations and is shaped by material settings and cultural conventions (Sheller 226). In short, how one is supposed to feel about driving is historically and culturally conditioned. Thus, in the United States the romantic, affective belief in the car as "an expression of and an instrument for speedy movement around and across the continent and up the social scale" (Boorstin vii) derives from historically-fashioned national myths of self-reliance, individualism, and pioneer spirit within the seemingly endless expanses of the American wilderness.

9 This is not to deny that cars provoke personal responses, too: for Essrog, highway driving is "maximally soothing" because the constant checking of mirror and "nudging of gas pedal" subsumes his motor tics (Lethem 251); for Genevich, by contrast, haunted by the fatal crash, driving is "an accident waiting to happen," the micro-movements and the need for constant vigilance merely a recipe for dangerous tiredness (Tremblay 199). Sheller's point is that individual and broader cultural affects intermingle in the "emotional agent" of the driver moving through space: "An emotional sociology of automobility can contribute to theorizing the connections between the micro-level preferences of individual drivers, the meso-level aggregation of specifically located car cultures, and the macro-level patterns of regional, national and transnational emotional/cultural/material geographies" (Sheller 223). Thus the driver generates unique "emotional geographies" (228) in the negotiations between different scales of experience.

Profoundly relational, moving through and connecting different realms, Sheller's emotional driving agent corresponds in many ways with Richard Randell's assembled entity the "autoself," which, following Erving Goffman, is "the product of social performances" on the road (Randell 664). The driver is not simply a subject, the car not simply a tool, but the hybridized "autoself" an embodiment of "everyday activities, practices and interactions"-or "microsociologies" (673)-that must be considered both at an individual level and collectively, as participants in a wider regime of automobility shaping contemporary identities. Evidently, the autoself embodies inherent tensions, which I address in more detail in my reading of the novels in connection with neurological conditions-between mobility and immobility, freedom and regulation, attention to the needs of others (a crucial aspect of vulnerability) and a lack of social "face-work" (Randell 667). However, one of Randell's principle insights is that the autoself should not be viewed, as critics such as Urry do, as "deficient" or attenuated in relation to the self engaged in face-to-face interactions, or as lacking norms of social etiquette (Randell 668). Rather, automobility, "an ongoing, contingent accomplishment," produces its own sociality and etiquette that have in turn led to the subordination of other social activities in the automotive landscape (668).

11 What one frequently sees in literary depictions is that-in part because of its production of a unique, emergent etiquette and set of behavioral dispositions-driving functions as a richly reflective spatiotemporal zone of activity, in which protagonists explicitly think about their social interactions; their allegiances to the places through which they drive; the haunting of the present by the past; and the "states of consciousness" characteristic of the contemporary world (Pierce 96), as well as the 
affective and symbolic qualities of driving itself. Far from forming a cocoon or strict barrier against the world outside, the car reconfigures the autoself's perceptual relationship with the world in a way that embodies many of its most salient features: kinaesthetic, mobile identities; feelings of distraction and vulnerability; reliance on technology. As Lynne Pierce argues in her discussion of Mancunian detective fiction: "how the world is seen from the window of the car interacts with the driver's (or passenger's) sense of being in the world more generally in ways that are indicative of the cultural and historical moment in which they reside" (Pierce 96). Just as feelings like a desire for escape, or nostalgia, or frustration are intensified in the closed space of the car, so the landscape, viewed at different speeds, becomes what Pierce, following Marcus Doel, calls a "scrumpled geography" (Pierce 97)-an authentic representation of the ways in which the contemporary world orders, folds and appears to compress time and space. Literary texts, adept at revealing protagonists' consciousness, emphasize the metaphorical possibilities of the "moments in time" experienced while driving (Pierce 100 ), such as the "the scene glimpsed in a rear-view mirror" (Pierce 105) that suggests, variously, a trajectory from past to future, from humble origins to full potential, from trauma to recovery.

In Motherless Brooklyn and The Little Sleep, the literary qualities of driving as an activity producing distinctive microsociologies and modes of perception combine with the vulnerable protagonists' neurological conditions, which have their own literary attributes-linguistic exuberance in Lethem's novel and the potential for narrative disruption in Tremblay's-to produce unique emotional geographies. These can be called "scrumpled" geographies in the specific sense that for these protagonists the past is consistently folded in upon the present, both mentally and in the physical evidence of the landscapes they traverse, and in the wider sense that through Essrog and Genevich (and their car journeys) we can induce certain hypotheses about community belonging, nostalgia, temporality and urban change in late-capitalist American society.

\section{Motherless Brooklyn: Motormouth and Autobody}

Motherless Brooklyn, a novel whose first chapter is called "Walks Into," whose first line is "[c]ontext is everything" (1) and whose last is "Tell your story walking" (311), builds on a tension between movement and fixity, mobility and adherence to particular locations that, according to Tony Tanner, is characteristically American. Writers in the USA, he argues, wrestle with a "quite fundamental paradox: that to exist, a book, a vision, a system, like a person, has to have an outline-there can be no identity without contour. But contours signify arrest, they involve restraint and the acceptance of limits" (Tanner 17). In Lethem's prize-winning detective story, the paradox Tanner describes is played out on several, related planes. First, it emerges thematically, in the story of an idiosyncratic individual, Lionel Essrog, imbued with the freedom to narrate in a unique style (to tell his story walking, as it were), but whose story is one of significant restrictions imposed by his neurological condition, his orphanhood, and his sentimental attachment to Brooklyn. Secondly, it emerges metagenerically, in the conventions of the hardboiled thriller that would themselves seem to delimit Essrog's range of possible activities, and of which the narrator demonstrates full awareness: "Detective stories always have too many characters anyway. And characters mentioned 
early on but never sighted, just lingering offstage, take on an awful portentous quality. Better to have them gone" (119). Finally, it emerges linguistically, in the "freak show" of Essrog's Tourette's symptoms (82) that shapes his relationships both with other characters and the reader of his text. In what follows I explore the tension between movement and restriction in these interacting planes and how they relate to Brooklyn as idiosyncratically imagined by the narrator. I argue that for all the frenzied movement of the Brooklyn streets and his linguistic outbursts, Essrog, "a walking joke" (83), is destined to go nowhere until the cracking of the case frees him from certain fixations. In a novel in which a lot of driving takes place and a lot of automotive metaphors take root, cars assume significance in Essrog's quest to gain agency, to overcome his automatic behaviours and fossilised attachments, to, as it were, "unscrumple" his emotional geography.

In the early stages of the story, "movement" acquires euphemistic meaning. Plucked by Frank Minna from St. Vincent's Home for Boys, Essrog and the other "Minna Men"Tony, Gilbert and Danny-become engaged in "moving work" for Minna (who works for the mysterious Matricardi and Rockaforte): the transportation of stolen goods (50). Later, once Minna has returned to Brooklyn after a mysterious two-year absence, we learn that "L\&L Car Service-it wasn't really a car service. That was just a front. L\&L was a detective agency" (88). Moving is either substituted for something else, or else the promise of "moving on," leaving behind the privations of orphanhood, is restricted or denied. The death of the substitute father Minna (33), whose surname derives from the Germanic for "love" or "care," represents Essrog's biggest impediment to moving on (though it does of course provide him with his first substantial case), but Minna himself can also be regarded as a euphemistic substitute. St. Vincent's "is essentially set on the off-ramp to the Brooklyn Bridge, but out of sight of Manhattan or the bridge itself" (36); thus Minna's rescue promises escape to wider horizons. And yet the "moving work" he provides mostly restricts Essrog and his companions to a tiny sphere of local operations and ideals: "rarely far from Court Street" (3), which is "a placid ageless surface alive underneath with talk." This, according to Essrog, "is the world we would come to know through Minna" (55, italics added).

15 A place of "unspoken understandings," Court Street hosts a barbershop where "the price of a haircut hadn't gone up since 1966" and "the Barbicide hadn't been changed since the product's invention": it is a place of "conspiracy" and "trust" and longestablished ritual (55). Its agelessness constitutes its chief appeal to both Minna and Essrog; the adherence to ancient behaviours is what makes it "the only Brooklyn, really" and distinguishes it from Brooklyn Heights, which is "secretly a part of Manhattan" and the "unspeakable barbarian tumult" east of the Gowanus Canal (56). "[C]itadel Manhattan" (25) stands for a brand of amnesiac, future-oriented aspiration at odds with Brooklyn's perceived embrace of its history: Essrog dismisses the clientele of the gentrified Boerum Hill Inn, for example, as "Manhattanized," "oblivious to the neighborhood's past and present reality" (239).

For this reason, Bent Sørensen's claim that “to the Tourette's sufferer, the whole of New York, from its subway system to its social hierarchies, resembles a Tourettic body, always in motion, never going anywhere with teleological certainty" (4) requires qualification. In Essrog's personal schema, this is true of Court Street, Brooklyn, but not of Manhattan, or indeed any other part of New York City. It is a schema that derives from one of Lethem's "hoariest set-pieces"-the claim that Brooklyn is "my Tourette's," 
that the provocative street talk, the humorous negotiations which allow resident Brooklynites to "play at hostility" and "flirt with aggression" have become deeply inscribed on the author's character and are reproduced in Minna and Essrog (Peacock 2011). The latter is able to blend into Court Street life, to find a home, because his Tourette's is an only slightly amplified version of the linguistic playfulness and experimentation all around him; it is, indeed, shaped by and dependent on it. And Minna, the substitute father for the motherless son, embodies Court Street; its knowingness and playfulness, its withholding of secrets, and, most significantly, its language. From the mouth of Minna emerge insults of a distinctly Brooklynite and vaguely Tourettic tenor: he describes the orphans, among other epithets, as "boiled cabbageheads" (24) and "chocolate cheesepuffs" (60). As an "idiot[ ] of connectivity, overly impressed by any trace of the familial in the world" (74) and desperate to belong, Essrog is only too ready to embrace Minna and Court Street and to ally his condition to them. Leaving behind the "Nowhere" of St. Vincent's (37), where his Tourettic words remained "trapped like a roiling ocean under a calm floe of ice" (45), for the bustle and excitement of Court Street, he can finally release the flow of words: "it was Minna who brought me the language, Minna and Court Street that let me speak" (37). As Jennifer Fleissner argues, Essrog's tics constitute "a mode of mimesis" of an eccentric and ticcish world he finds comforting and familiar (Fleissner 391).

This is dangerous because unlike food, or Prince's music or, as we shall see, driving (2, $127,251)$, Brooklyn as a space ironically does not encourage Essrog to externalize and thus ameliorate his symptoms. Rather, his idealized emotional geography of Brooklyn is inextricably linked to his condition, because it is internalized and in a sense created by his verbal and motor tics; thus it precludes the possibility of externalizing his Tourette's for long enough to reflect on his losses and move on. As he admits soon after Minna's death: "If I didn't stem my syndrome's needs, I would never clear a space in which my own sorrow could dwell" (127). Brooklyn as co-created by Minna and Essrog cannot appease or quell these needs because it is symbiotically bound up in them, and so imprinted with Minna signifiers that it ends up simply feeling too small. The narrator himself becomes, in Bennett Kravitz's words, "a self-fulfilling prophecy" because "his symptoms emanate from specific cultural and social contexts" (Kravitz 175) from which he is reluctant to depart, partly due to his guilt over Minna's murder. And guilt, as Essrog says, has a Tourettic quality, always wanting to "reach into the past to tweak, neaten, and repair" (284).

Oliver Sacks stresses the temporal aspect of Tourettic symptoms implied by Essrog's comment: "tics are like hieroglyphic, petrified residues of the past and may, indeed, with the passage of time become so hieroglyphic, so abbreviated, as to become unintelligible" (Anthropologist 81). Despite the appearance of constant physical and linguistic motion, the urge to "placate, interpret [and] massage" Essrog identifies in his outbursts (1) might best be interpreted as a desire to recreate the "placid, ageless surface" of Court Street: a desire, in fact, to fossilize or achieve stasis, and not to "let go." What is ostensibly a contradictory Tourettic impulse, the messing of surfaces characterized by "too much perfection," the nervous "plucking at threads" $(1,2)$, is not in fact a desire for permanent disruption or change but rather a temporary impulse leading to further opportunities to repair and restore order. Thus Tourette's sufferers like Essrog, as Sacks states, are "no nearer for not being still... no nearer to anything by virtue of motion; and in this sense, motion is not genuine movement" (Awakenings 16-17). The apparent chaos of Essrog's "echolalia salad," seen in signifiers such as "Don't 
know from Zendo, Ken-like Zung Fu, Feng Shui master, Fungo bastard, Zen masturbation, Eat me!" (4) connotes not fluidity or vehicularity but a desire to fix, not progress but a series of euphemistic or dysphemistic substitutions for the same idea that in the Jamesonian sense of a "breakdown in the signifying chain" can be called schizophrenic. They initiate "an experience of pure material signifiers, or, in other words, a series of pure and unrelated presents in time" (Jameson, Postmodernism 25-26).

Seen in this way, the impulses of Essrog's linguistic irruptions are entrenched in his vision of a romanticized Brooklyn imbued with the spirit of Minna and the past and always on the verge of obsolescence, "an everyday life that already felt nostalgic" (230). In times of high stress, for example during a confrontation with Tony, whom he suspects of being involved in Minna's murder, Essrog recognizes how debilitating his attachment to the borough has become: “Ordinarily I savored Brooklyn's unchangeability, the bullying, Minna-like embrace of its long memory. At the moment I yearned to see this neighborhood razed, replaced by skyscrapers or multiplexes. I longed to disappear into Manhattan's amnesiac dance of renewal" (179). Subsequent events reveal that what Essrog craves (and eventually arrives at) is not, in fact, Manhattanization-the willed amnesia of future-driven, capitalist aspiration; nor is it gentrification, which has its own complex relationship with the fossilised remnants of a gritty, "authentic" past. ${ }^{1}$

Rather, in a novel which, as Pascale Antolin observes, draws on the conventions of the bildungsroman (Antolin 3), his coming-of-age ultimately consists not in finding his voice via Minna's Court Street, placing the Touretter centre-stage in an act of "enfreakment" (Antolin 11), but instead in understanding another kind of "renewal"; a Brooklyn redefined through its wider national and global connections.

Driving (though not of the euphemistic kind described earlier) is instrumental to the process of renewal, as it is in Tremblay's The Little Sleep. It is not coincidental that the "Auto Body" section, in which much of Essrog's most narratively significant automotive experiences occur-the overnight stake-out outside the L \& L storefront and his pursuit of Tony and a murderous giant along the highway to Maine-starts with a conversation between Essrog and Frank Minna's older brother Gerard in an Upper East Side Buddhist Zendo. We learn that the Zendo is owned by a global corporation called Fujisaki, and that Frank was murdered by their giant hitman for stealing from them (232). Fujisaki, "ruthless and remorseless-in the manner of corporations," as Gerard wryly observes (233), pays the mortgage on the Zendo in return for certain services from Gerard and his students, thus casting this Buddhist practice as a vision of universal oneness corrupted by the corporation's desire for global domination of the market. During this conversation, Essrog confirms the wider geographies of the case and of his mentor's activities, and so begins the vital work of reimagining Court Street, Brooklyn as one tiny part of a network of global forces. As Essrog speculates: "Minna's death might be the first blow in an international wave of executions" (250).

To follow Tony and the giant, Essrog borrows a Tracer from L \& L. The vehicle's name is apt, connoting Essrog's investigative activities, the shift from his earlier desperate attempts to trace familial connections (in calls to other Essrogs in the phone book [68-9]) to his present tracing of global connections, and also the temporal aspect of the trace: the sense of a mark or object hinting at what was there before. In all senses, the suggestion is that Essrog's journey in the Tracer, which takes him to the Maine coast where sea urchins are caught for Japanese dining tables, is pivotal and transitional. 
Past "the airport exits" in Queens and over the Whitestone Bridge, Essrog's Tracer tails the giant (who tails Tony) into New England, the experience "of being farther out of New York City" than ever before serving "to keep [him] awake" $(250,251)$.

Despite his lack of sleep, his alertness is also maintained by "a Tourettic fantasy" he conjures while driving, and which symbolizes the transition from the spatial and emotional geographies of his previous life to the life to come. He fantasizes "that the hoods and fenders of the cars were shoulders and collars I couldn't touch. I had to keep adequate distance so I wouldn't be tempted to try to brush up against those gleaming proxy bodies" (254). Remembering Lynn Pierce's argument that modes of being in the car highlight ways of being in the contemporary world, one can argue that the "proxy" autobody participating in "the social world of automobility" (Randell 670) encompasses the tensions of vulnerability. At the same time it represents difference, it also provokes from the driver an act of recognition of sameness based around a paradoxical conflation of independence and mutual dependence. On the highway, Essrog is experiencing a new kind of relationality through prolonged engagement with wider “'publics' based on trust, in which mutual strangers are able to follow such shared rules, communicate through common sets of visual and aural signals, and interact even without eye-contact in a kind of default space or non-place" (Urry 29). Essrog understands that driving demands what Russell Beattie and Schick call "vulnerable judgment" (12), a form of critical self-reflection and ethical practice based on an understanding of the reciprocal vulnerability and interdependency of self and other. Vulnerable relationality involves and demands distance as well as proximity, a different kind of connectivity within spaces of shared dependence that stretch beyond the narrowly-conceived home neighborhood and which cannot be reduced, resolved, or internalized in Essrog's customary, autonomic ways.

The result is a renewed sense of attention and intention on Essrog's part, a fundamental shift in the meaning of "Auto Body." As he crosses the bridge at Portsmouth into Maine, he determines to jettison the convulsive body of tics and jerks and become a creature of pure intentionality: "I focused everything I had left on the drive, on casting off unnecessary behaviors, thrusting exhaustion and bitterness aside and making myself into a vehicular arrow" (262). Although he earlier acknowledges that his "craziness" feels "intentional" (47), the apparent contextual intentionality of Tourette's symptoms such as coprolalia are, as Brown and Kushner argue, of a different order. They "occupy an order of time that cannot be located: ongoing now, yet not fully immediate. As a vocalization that is circumstantial, yet convulsive, fundamentally at odds with articulate speech, indeed issuing from a different part of the brain, coprolalia is both now and not present" (Brown and Kushner 556). In Essrog's case, they are "not present" in their correspondence to, indeed emergence from, the fossilized behaviors of Court Street. The Essrog autoself, in contrast, moves intentionally through time and space, vulnerable and aware of others' vulnerability, toward a particular goal.

When Essrog eventually leaves the car in Maine and contemplates the ocean, he experiences a moment of the sublime. Tacitly acknowledging that Brooklyn is a text of his own creation, or a map drafted through his own tics and obsessions, he says: "Waves, sky, trees, Essrog-I was off the page now, away from the grammar of skyscrapers and pavement" (264). The "loss of language" he experiences, the "great sucking away of the word-laden walls I needed around me" (264), forces him to "reply in some new tongue, to find a way to assert a self that had become tenuous, shrunk to a 
shred of Brooklyn stumbling on the coastal void" (264). What he does, remarkably, is intentionally to shout some of his recurring tics ("Bailey!," "Eat me! Dickweed!") across the ocean, culminating in an ironic yet hugely significant proclamation of ownership: "I claim this big water for Essrog!" (265). The reassertion of his non-Tourettic self as his Brooklyn self dissipates suggests strongly that a more permanent departure from the borough-psychologically, if not literally-will be beneficial to him, by relieving him of his fixation on the past. The vastness gives him the space to mourn properly, to externalize his symptoms away from Court Street's claustrophobic significations.

After defeating the giant and piecing together the full story behind Minna's murder with Minna's wife Julia, Essrog does of course return to Brooklyn (303). Before he leaves, however, he flings the detritus of the case-his and Julia's guns, his cell phone, Minna's pager-into the ocean in a symbolic act of catharsis and consignment of the past to the past (albeit one partly driven by physical compulsion). In a typical moment of tragicomic bathos, he is forced to throw away one of his shoes, too, in order to honor the number five that happens Tourettically to be haunting him that day (303). Yet the absurd image of his driving "with [his] gas-pedal-and-brake foot clad only in a dress sock, back to Brooklyn" (303) only partially hides the deeper resonances of the incident. For the detective has, in a sense, left part of himself behind in the languagedefeating ocean. Moreover, the unclothed foot is a further image of the productive vulnerability engendered on the highway, and an ironic revision of Minna's exhortation to tell one's story walking.

There are ultimately signs that Lionel's restricted outlook might be changing. After the resolution of the case, the Minna Men call themselves detectives, but they have no clients, and so instead operate as a proper car service for the first time: "moving" is no longer a euphemism. Lionel's investigative impulses, having been the means by which he could attempt to arrest time and keep reaching into the past, have been banished, and he now engages in driving that strongly suggests mobility. The fact that he takes a trip to JFK Airport at the end of the novel also connotes a broadening of horizons (310). As Sørensen suggests, Esrog's new-found love of the chicken sandwich sold at the "kosher-food stand called Mushy's, run by a family of Israelis" (Lethem 310) hints at a reconnection with the Jewish roots signified by his surname (the esrog being a citrus fruit used at the harvest festival of Sukkoth), and thus with a community that crosses neighborhood, city and national boundaries (Sørensen 6). Thus Lionel's closing demands to Bailey, the mysterious, murdered lawyer Ullman and to the reader signify a rejection of their "ghosts" and a redoubled intent to spend less time obsessing on "dead men": "Put an egg in your shoe, and beat it. Make like a tree, and leave. Tell your story walking" (311). Lionel Essrog, it seems, has chosen to tell his story driving.

\section{The Little Sleep: Roads to the Past}

In Motherless Brooklyn, as I have shown, the tension between movement and rootedness imbricates with a tension between willful amnesia (associated with Manhattan) and a tenacious drive to remember (associated with Brooklyn) that approaches obsession, or a desire to inhabit the past. The attempt to resolve this tension is the very substance of private investigation, making an unlikely detective of Lionel Essrog. In narcoleptic Mark Genevich, Tremblay presents a protagonist whose neurological condition exacerbates this tension: the detective's amnesiac "little sleeps" both increase the 
urgency of remembering and render his attempts to remember, and thus his narrative, fragmented, surreal and unreliable. That these are the characteristics of memory itself is the novel's saddest and most profound irony, and irony, as the narrator muses, is the "narcoleptic's lot" (53). If The Little Sleep shares with Motherless Brooklyn its metageneric asides on detective conventions and disquisitions on the narrator's disorder, it extends the self-reflexive metanarrative tendencies by revealing entire episodes to be hallucinations, in which characters are substituted, events disordered, and the genre's realist veneer scrubbed away to uncover a much more expressionistic mode of storytelling. Thus, the extended climactic exposition common to so many detective thrillers in this case serves to destabilize the reader's understanding of previous chapters, even as it ostensibly explains "what happened": it lays bare the fact that the novel is a roughly stitched-together tapestry of recall, dream-work and amnesia. And so, in a story that consistently employs driving as a metaphor for memory, reading, the interpenetration of past and present, and the vulnerability attendant on both forgetting and remembering traumatic events, the "roads to the past" (217) are made difficult to navigate diegetically, emotionally and hermeneutically.

The first two chapters plant several clues to this disordered navigation. On initial inspection, the situation is comfortingly, and knowingly, familiar: in an insalubrious South Boston office, a private eye, wearing a fedora and "trying too hard to be anachronistic or iconoclastic, not sure which" (2), sits opposite a woman seeking his help and passing him a manila envelope containing two photographs. She is Jennifer Times, "singing contestant on American Star" and "daughter of the Suffolk County DA" (1). That she becomes, for Genevich, inextricably linked to his preoccupation with the past is signaled by her surname: the fact that "her legs go from the north of Maine all the way down to Boston" (1-2) reinforces the sense that this detective tends to view others in chronotopic terms, as implicated in his personal emotional histories and geographies. The generic familiarity turns to surrealism when Times shows him a bandaged right hand and claims: "I woke up like this yesterday. Someone stole my fingers and replaced them with these"' (3). If the opening scene assumes the qualities of a dream, it is partly because, as Genevich soon surmises, "the stuff about her missing fingers was part of a hypnogogic hallucination" (6) and partly because Times has been recruited, as readers discover, into the detective's personal imaginary: a realm involving his car accident, his deceased father Tim's former friendship with the DA, and his deep-rooted, traumatic attachment to "Southie" (28).

What subsequent events reveal is the true salience of Genevich's observation that he is "trying too hard to be anachronistic." First, he comes to realize, much later, in a dramatic confrontation with the chief villain of the story, that it was another character -Brendan Sullivan-who came to his office with the photos rather than Jennifer Times. Secondly, his initial assumption that Jennifer Times is the abused woman in the photographs constitutes a misreading of their age. Moreover, his reflections on these images are consistent with his ambivalence about photographs more generally. They are "old and heavy with passed time... imperfect... like my memories" (7) and saturated with elusive significance. Most of all, they are inadequate substitutes for recall. Reflecting on Tim's death and his recurring dream about him, Genevich observes that memories of his father "have faded to the edges, where recollection and wish fulfillment blur," or have been "co-opted by images from pictures. I hate pictures" (35). Genevich's confusing substitution of Jennifer Times for Sullivan as well as the 
woman in the photographs is homologous to the many imperfect representations substituting for memory found in the novel, those that attempt to fill "the unconscious space" between self and event which, the narrator laments, grows bigger with every little sleep (35). Ellen, his mother, attempts similar substitutions: after her husband's death, she opened "a photography studio and antiques shop" in Osterville, on Nantucket Sound (26).

31 After his hypnogogic vision of the DA's daughter offers him ten thousand dollars to find answers, Genevich slips into a micro-sleep (4). When he comes to, the evidence of his desk provides additional clues to the novel's deep metaphorical association between driving, memory and the imperfect representations of past experience that bedevil the narcoleptic detective's attempts to solve the crime and thus come to terms with his own traumatic past. In an intertextual allusion to Roger Wade's drunken, subconscious writing in Chandler's The Long Good-bye, Genevich wakes to discover "gouges and scratches in ink" on his notepad, which is colored "yellow like the warning traffic light" (6). (This presages the danger of the "red car," occupied by "goons from the DA's office," that tails him later in the story [72].) In a further significant simile, one which foreshadows a perilous car journey to come, he compares the "[a]utomatic behavior" of note-taking in his sleep to "driving and listening to the radio instead of actually driving, getting there without getting there" (8). If these observations bear some resemblance to Jean Baudrillard's description of driving as "immobility, concealed beneath the very intensification of... mobility" (7), then the resemblance is reinforced in the image of the notepad the detective helpfully reproduces for us (8). A mess of numbers and arrows pointing in different directions, with the words "South SHORE PLAZA" (where Genevich believes Jennifer Times is to appear the following day) surrounded by a lopsided fan of outward-pointing arrows, these doodles suggest a mind desperate for movement, away from Boston, but uncertain of the precise direction. Like Essrog's linguistic vehicularity, Genevich's scrawls suggest motion without arrival. The inclusion of two figures rendered like impossible dates-"27/49" and "32/47"connotes equal uncertainty over time (or "Times"): a scrambled, unintelligible chronology warped by narcoleptic dreaming and trauma. Thus the top page of the notepad assumes a chronotopic character and invites literary criticism of a psychoanalytical hue: reading unconscious doodles as complex symptomology.

That the DA's daughter is actually appearing at Copley Plaza in downtown Boston is irrelevant: what matters is the morphological connection between "South" and "Southie," the former centrally placed on the notepad, the latter central to the case and to the detective's obsessions. (And as we later discover, there is a body buried under South Shore Plaza). For Genevich, as for Essrog, context is everything. Southie, as place and sensibility, is at the heart of the case, which uncovers a horrific crime committed by childhood friends DA William "Billy" Times, Tim Genevich and Brendan Sullivan, and of the protagonist's troubled memories of his father and the neighborhood where he still lives in Ellen's inherited brownstone. His mother embodies the ancient, down-home community values of the area: "Ellen is Southie born and bred and, like every other lifelong resident, she knows everything about everybody. Gentrification has toned down the small-town we-are-Southie vibe a bit, but it's still here" (25). As well as proving useful for the case, Ellen's local knowledge and adherence to ancient Southie culture serve as a model to her son, whose inability to shake off past behaviors and adherence to a fossilized notion of Southie identity dictate the emotional geographies of a case that restricts itself to a narrow field of operations: South Boston 
and Osterville, seventy miles from the state capital, where Ellen's photography business and "the old homestead," the Genevich family bungalow, are located (166).

Shuttling between these locations-initially in taxis (often driven by "Osterville's only off-season cabbie," Steve Brill [138])-Genevich enacts contradictory "emotional configurations" symbolized by automobility (Pierce 98). His professed desire to uncover the "metaphorical skeletons" of the past (169) battles with the unconscious operations of his automatic self-the micro-sleeps that impede or distort memory and place him further from the past. For much of the novel, all Genevich can do is repeat these symbolic journeys (automatically, as it were) between locations saturated with elusive significance, always at risk of falling asleep and missing something important, always vulnerable to attack by the DA's enforcers or the traumatic repetition of his previous car accident. Far from allowing him to break free, mobility within this charged emotional landscape, this scrumpled geography, is prompted by traumatic stressors, "the grease in the wheel of my more disruptive narcoleptic symptoms" (39). Mobility represents "the almost total surrender of personal freedom for most of the journey" (Banham 217), both within the material space of the car and within the imaginative chronotope that dictates his movements. Until he dares to take the wheel himself, as we shall see, these journeys are equivalent to the automatic scrawlings on his notepad.

Within the cathected space Genevich traverses between South Boston and Osterville, the former's gentrification assumes increasing importance as the story unfolds. Although The Little Sleep makes fewer explicit references to it than Motherless Brooklyn, gentrification nonetheless carries psychological and metaphorical weight. Less interested than other contemporary fictions in material alterations to the urban landscape such as shop frontages and the construction of luxury apartment blocks (despite a brief reference to the "seventeen overpriced restaurants" in Quincy Market [38]), Tremblay is more concerned with gentrification's "ability to erase collective memory" (Moskowitz 176) and with what Sara Schulman calls "the gentrification of the mind." This she describes as a "diminished consciousness" unable or unwilling to conceive of and articulate "complexity, difference, dynamic dialogic action," and passive in the face of gentrification's homogenizing forces (Schulman 14). As in Lethem's writing, and in much recent crime fiction set in gentrifying neighborhoods, this often manifests as willed amnesia on the part of characters with a vested interest in the erasure or replacement of the past, standing in contrast to the detective's need to remember (and in this case his traumatically-induced, unwanted amnesia). Considered in light of The Little Sleep's automotive metaphors, the gentrified mind represents a desire to "move on" potentially even more dangerous than the protagonist's constant driving along roads to the past.

35 A powerful public figure, ostensibly devoted to the prosecution of justice while strenuously working to avoid justice for his own misdemeanors, DA Times is the novel's most malevolent example of the gentrified mind. The nomenclatural slippage from "Billy" to "William" connotes the move from youth to adulthood, past to present, from teenage bully and tearaway to respectable citizen and, most significantly (for Genevich, certainly), from working-class "lord[ ] of Southie" (247) to life among the professional middle-classes in bourgeois Boston. That he nonetheless retains a residual allegiance to a nostalgic, old neighborhood identity is revealed in an early scene when he confronts Genevich, asking the detective to give him the photographs. Genevich taunts him: "What would my dear old dad say about you harassing his son like this? It's not very 
Southie of you," provoking a cruel reminder that Tim is long dead and a sharp retort - "And don't tell me what's Southie, Genevich. You have no idea" (96). Subsequent revelations force Genevich to accept the unpalatable truth that the ostensibly dissonant visions of Southie represented in this scene-one of comradeship, neighborhood solidarity, community values and the other of cruelty, bullying and abuse-are very much intertwined. To employ a metaphor suggested by Genevich's narration in this scene: the townies may sit "on one side" of the bar and "the trendies on the other" (93), but they nonetheless inhabit the same bar. In other words, visions of old and new, past and present, gritty and sanitised inevitably inflect each other.

This truth is further illustrated by the detective's recurring "Dad-in-the-backyard dream" (52) in which a young Mark and his father "walk around the yard picking up dog shit" (35). Both analeptic and proleptic, the dream provides significant clues to future breakthroughs in the case, while simultaneously revisiting a symbolic version of the past and enacting a working-through of Genevich's unconscious ambivalence about his father. In the dream, young Mark is prohibited from entering the shed: "There are too many tools, too many ways to hurt myself" (35). The tools represent a sublimated version of the film canister Genevich eventually discovers in the same shed (179), the vital evidence which cracks the case, implicates the DA and explodes the detective's memory of his father. The excrement, in turn, is a deeply paradoxical image. On the one hand, it suggests a need to confront the filthy actions of the past, and on the other it is consistent with a desire on the part of characters including Tim Genevich and Billy Times merely to be seen to clean up one's act, a desire which corresponds to the smoothing-over instincts of urban gentrification and to Schulman's "gentrification of the mind." Such a desire is signified by the father's unwillingness in the dream to utter the word "shit" in front of his son, his preference for euphemisms such as "poop" and "Natural fertilizer" (36). Thus the dream, in the classic Freudian tradition, participates in the encounter with trauma and the simultaneous avoidance of its most distressing aspects.

However, as the detective approaches a clearer understanding of his father's role in the crime, later versions of the dream are infected by the case and imbued with greater menace and sadness. First, the five-year-old Mark directly asks his father where the film is hidden, jamming his foot between the shed doors, emphasizing his desire to uncover its secrets (173). And in another paradox, the father responds to the son's question, "Who are you?" with "You don't know, and you never will" (173); part of the process of reconciliation with the past is in accepting its elusiveness and unknowability. A final version of the dream replaces the excrement with charred pieces of detritus from the case-Tim's tools, "a projector, a screen, and a film can" and "other pieces burned beyond recognition" (260). Accusing his father of cowardice, Mark realizes that he has to "clean up the mess by myself" (261). Though such sentiments lack the "ring of authenticity" because the younger Genevich considers himself a coward, too (261), they at least indicate that the process of gaining control over his relationship with his father, of mastering his memories, is approaching a conclusion, albeit an ambiguous one. The ambiguity derives in large part from the fact that this apparent control emerges during sleep, the automatic self's zone of activity, which Genevich as a narcoleptic is singularly ill-equipped to control, and which marks his increasing distance from events. 

Osterville, where Genevich collects an antique film projector from his mother's shop and culminating in the symbolic drive "back to Southie and my apartment" (210), this journey is predicted by the automotive metaphors that permeate the novel, and by an earlier driving episode that turns out to have been hallucinated. Following an interrogation and minor beating from the DA and his goons in Times' limousine, the detective escapes into a nearby unlocked taxi. After fumbling with the gears, he eventually pulls away, gunshots ringing in his ears (99), only to wake up later in the same taxi with the cabbie in the front seat and realize that the driving and the gunplay were hypnogogic visions. Here Genevich can only hallucinate a rehearsal of his climactic road trip because at this stage, without sufficient understanding of past events and still too immersed in a romanticized vision of Southie, he lacks autonomy: understood here as the ability to reconcile his conscious and unconscious impulses, his waking and automatic selves, and map out his complex historical and emotional geographies in an intentional manner, in much the same way that Lionel Essrog is able to externalize and intentionalize his symptoms through driving along the highway to the ocean.

Taking the wheel represents autonomy. On the one hand, it is an emotional decision to banish his personal demons; "going back to Southie" in the rented car "is the only way to finish the case. My case" (210). However, Genevich, in actively participating in the car-system, and in acknowledging the danger he poses to others within that system, recognizes that his personal quest must be enacted within a wider contemporary society of mobile individuals. Not only is the autoself a techno-human hybrid, it is also an "assembled social being" (Dant 74) that "produces a range of social actions" centered on the car and with profound effects on the landscape and on communities (Dant 61). Though sardonic, his self-motivating statement-"If millions of privileged stunted American lunkheads can operate heavy machinery, I can too" (199)_ demonstrates the narrator's awareness of his macro-level connections. He has joined "the flow of traffic, become part of the mass, the great unending migration, the river of vehicles" (199). Of particular significance here is the image of migration. $\mathrm{He}$ understands that the road "manifests a particular kind of flux-a movement of bodies and machines, of mechanical centaurs" (Alworth 95), and that movement through time and space is a constant and a shared human characteristic. This understanding is

European journal of American studies, 16-4 | 202 
engendered by the activity of the Genevich autoself and suggests psychological progress on the detective's part.

Thus the "OCD pattern" of mirror checks and "the eyes-on-the-road bit," though dangerous because it is soporific, is also vital. The "proverbial everywhere-at-once" required by driving (199) removes the detective from his personal obsessions and forces him to pay simultaneous attention to micro, meso and macro mechanical and social processes and levels of experience. Most importantly, he understands, as Essrog also does, that driving demands vulnerable judgment. Not only is he "on display, behind glass," visible and open to other drivers, but also they are open to his actions, all of them part of the "hive" of the congested roads (199), all of them linked. Despite grumbling that it is "more than a little depressing," it is while driving that Genevich muses that "[e]verything and everyone is connected" (217).

What results is a community formed from a mobile, attentive sociality and distinct from the fossilized conceptions of Southie and Osterville symbolized by the black-andwhite photographs Ellen keeps on her walls and the antiques filling her shop -"weekend treasures" for the bourgeoisie in search of purchasable authenticity, "useless junk" for Genevich, who this late in the story appreciates that "[s]ome things are meant to be thrown away and forgotten" (203). One object granted temporary exemption from this sentiment is the film projector, resembling "a mini-robot out of a 1950s sci-fi flick," that Genevich uses to watch the harrowing movie he finds in the family shed (205). As well as helping to conclude the case, its ability to show moving pictures distinguishes it from the still photos, objets d'art and pieces of furniture collected by Ellen and, within the novel's metaphorical framework, allies it to the driving that is pivotal in liberating Genevich from the past.

Likewise, the New England that Genevich, awake and attentive, sees from the car is a chronotopic region in motion, where historical and socioeconomic changes are revealed spatially and where the "everywhere-at-once" attention of the driver constitutes an idiosyncratic cognitive mapping of his own movements and emotions within the wider landscape. In comparison to the Osterville bungalow, a place of "family secrets" (166), "metaphorical skeletons" and "a collection of regrets, jettisoned and almost but not quite forgotten" (169), and the "sarcophagus" of the shed, rehearsed so often in dreams (176), the spaces and places Genevich travels through in the rental "space car" (198) are described not in terms prescribed by a personal imaginary, but in straightforwardly material and geographical terms that suggest socioeconomic changes and differences. Small details such as the "one-lane strip of pavement that runs between Ellen's building and the clothing boutique next door" and the lack of public parking near these stores (200) hint at neighborhood gentrification and the increasing privatization of space. Leaving Osterville, having picked up the projector, Genevich pulls into the car park of a deserted convenience store, and muses on the differences between the city and the suburb: "If this was Southie, the townie kids would be hanging out here, driving around and buzzing the lot because there's no other place to go. They'd spike their slurpies and drink hidden beers. But this isn't Southie. I'm not there yet, not even close" (211). Though the final sentence hangs heavy with the weight of his personal quest, it is nonetheless uttered in the context of wider observations on space and demographics.

Avoiding the highways to minimize the danger, Genevich goes on to provide commentary on the Sagamore Bridge, "a behemoth, seventy-plus years old" (213); 
Plymouth, "[t]he biggest city in Massachusetts by square mileage"; and "[q]uiet back roads that range from the heart of suburbia to the heart of darkness, country roads with no streetlamps and houses that don't have any neighbors" (216). A crucial part of assuming control, avoiding the "skulking-around shit" and finally "doing it my way" (211), is this increased attention to spaces in constant flux and interaction, the interim areas, transport networks and hinterlands that break the deeply imagined binary of Southie and Osterville (equivalent, perhaps, to the "excluded middles" Oedipa Maas finds so difficult to confront in The Crying of Lot 49 [136]). Such attention is vital because it expands the context of the case beyond the detective's personal preoccupations, because it has the potential radically to expand his conception of home and community, and because it staves off the biggest threat to his wellbeing-the regression into the dominant patterns of his automatic self. As he says: “This isn't good either. The whole trip is becoming a routine. I've been in the car long enough that driving is once again automatic behaviour" (217). It is soon after this statement that he crashes into a tree-a reenactment of the traumatic crash that prompted his narcolepsy. Crucially, this time he survives relatively unscathed, and, following "a neon and halogen path, [things] getting brighter," he hits the road again and this time fully surrenders his autoself to the flow of cars: "I let them box me in and go where the currents take me" (219). It is thus, symbolically reliving and surviving his trauma, and becoming an integral part of a wider community of citizen drivers, that he returns to his Southie apartment to watch the film, confront William Times (and time itself) and solve the case.

What follows involves a visit from the goons that might be another hallucination and a cataplectic Genevich testing his expository hypothesis on an ice-cold DA Times, followed by a fire that destroys the apartment, and a dramatic fall down the stairs, Genevich riding on Times' back (252). If this image metaphorically hints at a renewed ability to dominate the detective's greatest enemy, time, then the apartment conflagration (following soon after the collapse of the shed) signals the necessary destruction of debilitating childhood attachments, leading to a less fossilized and romantic, more flexible and expansive conception of "home" as a fluxuous concept that adapts over time. It is a conception partially enabled by the drive to Southie. Equally significant is the subsequent drive back to Osterville, during which he avoids another accident by choosing to take a couple of naps (255). This is a voluntary act equivalent to Essrog's shouted recitation of his verbal tics across the ocean, and hints at the future easing of Genevich's condition. If all of this evidence implies that our detective is now able, to a limited extent, to "move on," the downbeat ending of the novel shows that not everybody has the same ability. His mother keeps her still, black-and-white family photographs on the bungalow walls: "Ellen is determined not to forget, determined to keep her collected memories exactly where they were before, determined to fight against her very own version of the little sleep" (268). This final image of stasis, of a determination to remember that is paradoxically amnesiac in its refusal to acknowledge the changes all memories undergo as they move through time (though less malevolent than DA Times' drive to forget), stands in sad contrast to the son's newfound mobility. Mark Genevich has bumpily but successfully navigated the roads to the past and back again. 


\section{Roads to the World}

In Motherless Brooklyn and The Little Sleep the car proves itself to be "a means for liberating, enriching and empowering the self," if not exactly "an instrument of competition, pleasure, intoxication and moral renovation" (Emmett Ryan 116, 129). As I have shown, both novels put their troubled protagonists at the wheel for pivotal journeys that not only lead to resolutions of the cases, but to liberation from past events, and a qualified reappraisal of attachments to places and people. In neither case, of course, does driving offer total freedom from the protagonists' neurological conditions, even if Genevich's unproblematic journey to Osterville after the fire hints at alleviation of his symptoms. Rather, the "autobody" in Essrog's case offers a practical means of externalizing his symptoms through ticcish attention to mirrors and gear changes, as well as a real, material form of mobility to counter the illusory transitivity of his verbal symptoms. In Genevich's case, driving represents autonomy in the fusion of automatic and conscious selves and an opportunity (though one fraught with danger) actively to map and therefore alter the physical spaces previously available primarily as memories, dreams or hallucinations.

Moreover, in neither novel does driving offer liberation of a romantic, self-reliant, individualistic kind. Rather, the autoself in both stories is necessarily a "relational entity" (Sheller 222) within a complex system, who must exercise vulnerable judgment - proceeding from a recognition of one's inherent vulnerability, and of humanity's "essentially and starkly relational" state (Ganteau 2)-to negotiate a route with due attention to micro, meso and macro levels of experience. If this attention enables an "unscrumpling" of the detectives' geographies, it is of a productively ironic kind. While it helps to release them from narrow local attachments, it does so by showing how local, regional and global are compressed together and inform each other.

Therefore, automotive liberation is also inflected with tensions and irony. If driving can offer emotional geographies of fluidity and perceived freedom, it is only ever "an illusion of driver freedom" (Thrift 50), because one can drive only along prescribed routes; one is bound by motoring laws; the smooth flow of traffic is enabled by a complex system of technological control and regulation; and, most importantly, because one is bound by a duty of care to other autoselves. Returning to the quotation with which this article begins, driving happens within all these related, defined contours and thus requires "the acceptance of limits" (Tanner 18). And yet I argue that the road system and the behavior of autoselves as depicted in Motherless Brooklyn and The Little Sleep have a metonymic function, representing the wider contemporary culture of vulnerability, and that the limits are precisely what liberates. They do so by demonstrating how vulnerability is "both the condition and expression of interdependence" (Ganteau 11) and thus that what fundamentally defines and identifies the individual is vulnerable relationality.

Essrog and Genevich's vulnerability is partly exacerbated metagenerically, by their investigative activities, the conventions of their genre and their self-consciousness about generic roles. Detective fiction, through its entertaining of the possibility of collective culpability for criminal acts (partly for the purposes of suspense, partly as a matter of ethics) emphasizes relationality. And particularly in its hardboiled tradition, it emphasizes the world-weary detective's sense of risk, helplessness and even guilt in the face of larger forces beyond his or her control-such as urban transformation, the 
power of global corporations like Fujisaki, or political influence. As a result it exemplifies vulnerability's dual valences: the "positive apprehension" of relationality (Ganteau 166) which empowers through the recognition of shared precarity and risk and ties us more closely to others, and the feelings of destabilisation, disorientation and the jettisoning of the comforts of individual sovereignty that are supplementary to relationality.

50 And of course, as we have seen, vulnerability is an inevitable consequence of Essrog's and Genevich's neurological conditions. On the one hand, Tourette's and narcolepsy make detection difficult, in part because the vital intersubjective function of the private eye is threatened by a tendency to tic or twitch or fall asleep. On the other, if one considers these disorders in the context of disability studies, then one can argue for their crucially intersubjective role, in the sense that the physically or mentally disabled body is not an exception or a monstrous other, but rather "a common denominator of humanity" (Ganteau 5) and, in Margrit Shildrick's words, a reminder of "our body as children" (Shildrick 80) and thus of shared vulnerability and dependency. There are risks in such an approach, of course, not least of which is the implied universalization or metaphorization of individuals' unique sympotomologies. Nonetheless, it provides further justification for the representation of such individuals in the "neuronovel" as a phenomenon that offers unique insights into contemporary vulnerability.

51 Through lack of space (and lack of specific expertise), my approach in this article has not pursued the path of disability studies, vitally important though it is. Instead, my analysis has exploited the automotive metaphors in both novels to demonstrate, ultimately, the ironic significances of "autonomy" and the autoself in a late-capitalist world of mobility and vulnerability. The roads along which our eccentric, vulnerable detectives travel are vectors of contemporary vulnerability under capitalism and, whatever means they provide of escape in these stories, are not to be understood utopically. If the car-system is central to, and locked in with, "the leading economic sectors and social patterns of twentieth-century capitalism" and has transformed global landscapes, "movement, pleasure and emotion in the contemporary world" (Dennis and Urry 58), then the contradictions of driving this article has explored map and illuminate the tensions of vulnerability and the individual's relationship to space in a globalised world. To borrow Tremblay's phrase once more, the "everywhere-at-once" of the autoself, the attention to multiple levels of experience, demonstrates that, in Fredric Jameson's words: "the truth of that experience no longer coincides with the place in which it takes place... There comes into being, then, a situation in which we can say that if individual experience is authentic, then it cannot be true; and that if a scientific or cognitive model of the same content is true, then it escapes individual experience" ("Cognitive" 349). To take the wheel is to be both here and elsewhere and so to reconfigure one's sense of belonging. Likewise, the neighborhood to which one is attached is part of the world, and shaped by bigger forces. To get out of it, literally or emotionally, is to enter an even scarier and more disorienting place. 


\section{BIBLIOGRAPHY}

Alworth, D. J. Site Reading: Fiction, Art, Social Form. Princeton UP, 2016.

Antolin, Pascale. “'I am a freak of nature': Tourette's and the Grotesque in Jonathan Lethem's Motherless Brooklyn.” Transatlantica. Revue d'études américaines, vol. 1, 2019, pp. 1-20.

Banham, Reyner. Los Angeles: The Architecture of Four Ecologies. U of California P, 2000.

Baudrillard, Jean. America [1986]. Verso, 2010.

Böhm, Steffen et al., editors. Against Automobility. Blackwell, 2006.

Boorstin, Daniel. “Editor's Preface.” The American Automobile: A Brief History by John Bell Rae, U of Chicago P, 1965.

Butler, Judith. Precarious Life: The Powers of Mourning and Violence. Verso. 2004.

Chandler, Raymond. The Long Good-bye [1953]. Penguin, 2005.

Dant, Tim. "The Driver-Car." Theory, Culture and Society, vol. 21, no. 4/5, 2004, pp. 61-79.

Dennis, Kingsley, and John Urry. After the Car. Polity, 2009.

Doel, Marcus. "A Hundred Thousand Lines of Flight: A Machinic Introduction to the Nomad Thought and Scrumpled Geography of Gilles Deleuze and Felix Guattari." Environment and Planning D: Society and Space, vol. 14, no. 4, 1996, pp. 421-439.

Emmett Ryan, James. "Cars of Destiny: Writing the Golden Age of Motoring." Studies in Travel Writing, vol. 17, no. 2, 2013, pp. 116-132.

Fleissner, Jennifer L. "Symptomology and the Novel." Novel: A Forum on Fiction, vol. 42, no. 3, 2009, pp. 387-392.

Ganteau, Jean-Michel. The Ethics and Aesthetics of Vulnerability in Contemporary British Fiction. Routledge, 2015.

Jameson, Fredric. "Cognitive Mapping." Marxism and the Interpretation of Culture, edited by Cary Nelson and Lawrence Grossberg, U of Illinois P, 1988, pp. 347-360.

---. Postmodernism: or, the Cultural Logic of Late Capitalism. Verso, 1991.

Katz, Jack. How Emotions Work. Chicago UP, 2000.

Kravitz, Bennett. "The Culture of Disease or the Dis-ease of Culture in Motherless Brooklyn and Eve's Apple." Journal of American Culture, vol. 26, no. 2, 2003, pp. 171-179.

Lethem, Jonathan. Motherless Brooklyn [1999]. Faber and Faber, 2000.

Lothman, Timo, and Antje Schumacher. "Automobility in Poetry: A Conceptual Metaphor Approach.” Spatial Practices, vol. 17, 2013, pp. 213-229.

Meat Loaf. "Objects in the Rear-View Mirror May Appear Closer Than They Are.” Bat Out Of Hell II: Back Into Hell. MCA, 1994.

Moskowitz, Peter. How to Kill a City: Gentrification, Inequality, and the Fight for the Neighborhood. Nation Books, 2017. 
Peacock, James. "Why All the Marsupials? An Interview with Jonathan Lethem." American Studies Today Online, 6 March 2014: An Interview with Jonathan Lethem (americansc.org.uk). Accessed 15 Jan 2021.

Pynchon, Thomas. The Crying of Lot 49 [1965]. Vintage, 2000.

Randell, Richard. "The Microsociology of Automobility: The Production of the Automobile Self." Mobilities, vol. 12, no. 5, 2017, pp. 663-676.

Russell Beattie, Amanda, and Kate Schick, editors. The Vulnerable Subject: Beyond Rationalism in International Relations. Palgrave Macmillan, 2013.

Sacks, Oliver. An Anthropologist on Mars. Alfred A. Knopf, 1995.

---. Awakenings. Knopf Publishing Group, 1987.

Schulman, Sarah. The Gentrification of the Mind: Witness to a Lost Imagination. U of California P, 2012.

Sheller, Mimi. “Automotive Emotions: Feeling the Car." Theory, Culture and Society, vol. 21, no. 4/5, 2004, pp. 221-242.

Shildrick, Margrit. Embodying the Monster: Encounters with the Vulnerable Self. Sage, 2002.

Sørensen, Bent. "Jewishness and Identity in Jonathan Lethem's Motherless Brooklyn.” 2006, www.hum.aau.dk/ i12bent/Lethem.doc. Accessed 7 Nov 2011.

Tanner, Tony. City of Words. Harper \& Row, 1971.

Thacker, Andrew. "E. M. Forster and the Motor Car." Literature and History, vol. 9, no. 2, 2000, pp. 37-52.

Thrift, Nigel. "Driving in the City." Theory, Culture and Society, vol. 21, no. 4/5, 2004, pp. 41-59.

Tindall, Gillian. Countries of the Mind: The Meaning of Place to Writers. Hogarth P, 1991.

Tremblay, Paul. The Little Sleep. Henry Holt \& Co., 2009.

Urry, John. “The ‘System' of Automobility.” Theory, Culture and Society, vol. 21, no. 4/5, 2004, pp. 25-39.

Zukin, Sharon. Naked City: The Death and Life of Authentic Urban Places. Oxford UP, 2010.

\section{NOTES}

1. For one of the best discussions of this complex relationship, see Zukin. Lethem's novel The Fortress of Solitude, published in 2003, is also concerned with gentrification and the desire to hang on to an authentic neighborhood past.

\section{ABSTRACTS}

This article explores two detective stories featuring protagonists with neurological conditions. Lionel Essrog, the narrator of Jonathan Lethem's Motherless Brooklyn (1999), suffers from 
Tourette's Syndrome, and Mark Genevich, hero of Paul Tremblay's The Little Sleep (2009), has narcolepsy. Each character is unusually attached to his home neighborhood: Essrog to Court Street in Brooklyn and Genevich to South Boston. Indeed, Genevich still lives in his grandparents' brownstone. What is striking in both novels is how closely their conditions are also connected to these neighborhoods. Essrog's tics and outbursts mirror the chaos of his Brooklyn, but his obsessive, smoothing-over tendencies reflect his guilt over his orphan status, his desire to reach back into and repair the past. Genevich's narcolepsy keeps him in "Southie" partly because of his reliance on his mother and partly, in practical terms, because it is dangerous for him to drive. Most importantly, his unpredictable sleep puts "more unconscious space between [him]self and the events [he] experienced"-traumatically induced, his "little sleeps" are "fraudulent extra days, weeks, years," disruptions in time, when the past invades his dreams. It is significant that Genevich's condition arises after a car accident in which his friend was killed. In fact, cars are important in both novels. I argue that, as symbols of modernity and American mobility, cars signify in complex relation with the protagonists' homes and neurological conditions. The "auto body," to quote one of Motherless Brooklyn's chapter titles, puns on the involuntary, automatic behaviours of the tourettic and narcoleptic body, but also offers the possiblity of mobility both physical and metaphorical: an escape from the neighborhood and associated obsessions, a way for the detective to connect a wider set of locations and relations, to remap himself beyond the confines of a narrowly imagined community and the restrictions of his condition.

\section{INDEX}

Keywords: contemporary fiction, neuronovels, Tourette's syndrome, narcolepsy, automobility trauma, neighborhood

\section{AUTHOR}

\section{JAMES PEACOCK}

James Peacock is Senior Lecturer in English and American Literature at Keele University in the UK. He specialises in contemporary American fiction, and is the author of Brooklyn Fictions: The Contemporary Urban Community in a Global Age (2015) and the co-editor, with T. J. Lustig, of Dieseases and Disorders in Contemporary Fiction: The Syndrome Syndrome (2013). 